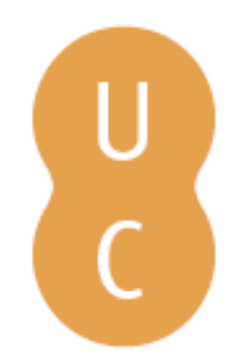

\title{
nombalina
}

\section{Configurações disciplinares e interdisciplinares da ciência da informação no ensino e pesquisa}

\author{
Autor(es): $\quad$ Pinheiro, Lena Vania Ribeiro \\ Publicado por: Imprensa da Universidade de Coimbra \\ URL \\ persistente: URI:http://hdl.handle.net/10316.2/31864 \\ DOI: $\quad$ DOI:http://dx.doi.org/10.14195/978-989-26-0319-3_9 \\ Accessed : $\quad$ 26-Apr-2023 12:09:53
}

A navegação consulta e descarregamento dos títulos inseridos nas Bibliotecas Digitais UC Digitalis, UC Pombalina e UC Impactum, pressupõem a aceitação plena e sem reservas dos Termos e Condições de Uso destas Bibliotecas Digitais, disponíveis em https://digitalis.uc.pt/pt-pt/termos.

Conforme exposto nos referidos Termos e Condições de Uso, o descarregamento de títulos de acesso restrito requer uma licença válida de autorização devendo o utilizador aceder ao(s) documento(s) a partir de um endereço de IP da instituição detentora da supramencionada licença.

Ao utilizador é apenas permitido o descarregamento para uso pessoal, pelo que o emprego do(s) título(s) descarregado(s) para outro fim, designadamente comercial, carece de autorização do respetivo autor ou editor da obra.

Na medida em que todas as obras da UC Digitalis se encontram protegidas pelo Código do Direito de Autor e Direitos Conexos e demais legislação aplicável, toda a cópia, parcial ou total, deste documento, nos casos em que é legalmente admitida, deverá conter ou fazer-se acompanhar por este aviso.

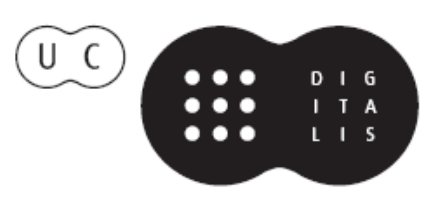


Maria Manuel Borges

Elias Sanz Casado

Coordenação

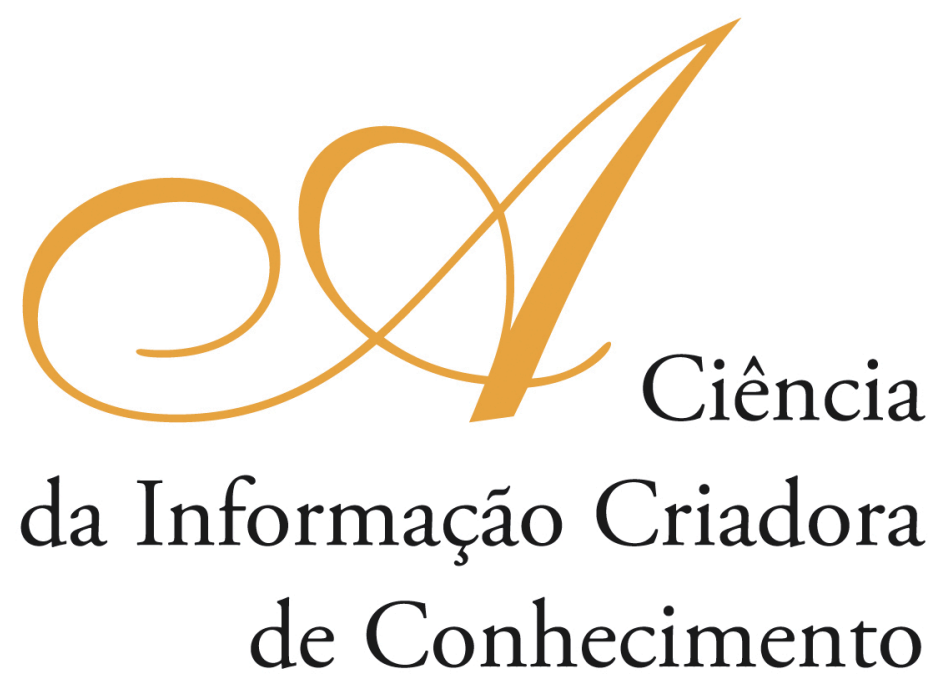

Vol. I

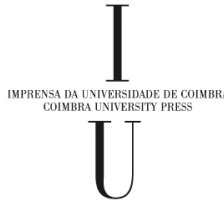

- COIMBRA 2009 


\title{
Configuraçốes Disciplinares e Interdisciplinares da Ciência da Informação no Ensino e Pesquisa ${ }^{\mathrm{I}}$
}

\author{
Lena Vania Ribeiro Pinheiro \\ Instituto Brasileiro de Informação em Ciência e Tecnologia, do Ministério de Ciência e Tecno- \\ logia (Brasil)
}

\section{Resumo}

Pesquisa sobre a interdisciplinaridade na Ciência da Informação, tendo por fundamentos teóricos sobretudo as idéias dos epistemólogos Hilton Japiassu, brasileiro, e Olga Pombo, portuguesa, no entendimento e reflexão sobre os conceitos de disciplinaridade, interdisciplinaridade e transdisciplinaridade. A construçáo científica da Ciência da Informação é abordada, em continuidade a pesquisas teóricas e empíricas anteriores, no mapeamento de disciplinas que constituem o território epistemológico da área. As nuances das fronteiras e limites, bem como a dinâmica de mutaçôes nas áreas interdisciplinares são estudadas no tempo, especialmente decorrentes da Sociedade da Informação, pela forte interferência da globalização e das tecnologias da comunicação e informação-TIC’s. As disciplinas mais consolidadas e as novas disciplinas surgidas pelo impulso da nova ordem tecnocultural, na década de 1990, permitem delinear os contornos da interdisciplinaridade, nos campos de conhecimento com maior contribuição teórica e prática para cada disciplina e no desdobramento da interdisciplinaridade, pela identificaçáo de cada campo do conhecimento neste entrecruzamento interdisciplinar. $\mathrm{O}$ núcleo de análise é a universidade, como entidade geradora de conhecimento, tendo por fonte da pesquisa os programas de pós-graduação em Ciência da Informação, com as respectivas áreas de concentração e linhas de pesquisa, na identificação de possíveis indícios interdisciplinares. A vinculação institucional dos Programas é analisada, para verificação, na estrutura acadêmica, de como e com que áreas são estabelecidos os laços interdisciplinares, dos mais fortes aos mais frágeis, no âmbito das universidades. A partir dos resultados é traçado um mapa do território científico da Ciência da Informação com suas interfaces interdisciplinares, tendências e mutaçóes ao longo do tempo, no ensino e na pesquisa.

\begin{abstract}
Research on the interdisciplinarity in Information Science using the theoretical basis - and mainly the ideas of epistemologists Hilton Japiassu, Brazilian, and Olga Pombo, Portuguese, for the understanding and reflexion on the concepts of disciplinarity, interdisciplinarity and transdisciplinarity. The scientific construction of Information Science is approached as a continuation of previous theoretical and empirical researches in the mapping of the disciplines which constitute the epistemological domain of the area. Nuances of boundaries and limits as
\end{abstract}

1 Trabalho parte do projeto de pesquisa: Correntes teórico-epistemológicas da Ciência da informação no Brasil e dinâmica de afluentes e efluentes, 2009-2012, coordenado pela autora deste trabalho. Apoio CNPq. Participa desta pesquisa Miguel Amorim Neto, como bolsista de iniciação científica do CNPq. 
well as the dynamics of mutations in interdisciplinary areas are studied in time, especially those emanating from the Information Society on account of the strong interference of globalization and of the information and communication technologies - ICTs (TICs, in Portuguese). The more consolidated and the new disciplines emanating from the new technocultural order in the 1990s, allow the outlining of interdisciplinarity in those fields with greater theoretical and practical contribution to each discipline and in the ramifications of interdisciplinarity, through the identification of each field of knowledge in this interdisciplinary crossing. The core of the analysis is the university, as a knowledge generator entity; data sources were graduate programs in Information Science with respective concentration areas and formal research lines for the identification of possible interdisciplinary signs. The institutional affiliation of programs is analyzed, in order to detect, in the academic structure, how and with which areas interdisciplinary bonds are established - from the strongest to the weakest - in the university context. Results allowed the mapping of the scientific domain of Information Science, with its interdisciplinary interfaces, tendencies and changes across time, in teaching and research.

\section{Introduçáo}

Este trabalho tem origem e dá continuidade a pesquisas teóricas e empíricas que vêm sendo realizadas pela autora desde os meados dos anos 1990. O esboço de uma configuração interdisciplinar da Ciência da Informação foi delineado no artigo "Traçados e limites da Ciência da Informação (Pinheiro e Loureiro, 1995), tomando como base as disciplinas ministradas no Programa de Pós-Graduação em Ciência da Informação (convênio IBICT-UFRJ), que em 1995 completava 25 anos de mestrado, o primeiro da área na América Latina. O doutorado se iniciara no ano anterior (1994), depois da experiência, desde o final dos anos 1980, como linha de pesquisa na área de Comunicação, até se constituir num doutorado autônomo e específico em Ciência da Informação.

Este ensaio de Pinheiro e Loureiro (1995), de um mapeamento de disciplinas do mestrado e os respectivos campos de conhecimento que contribuiriam para a sua construção e desenvolvimento epistêmico, ainda carecia de estudos que apresentassem com maior clareza e consistência as suas relações interdisciplinares. Esta constatação foi reconhecida por Pinheiro (1998) em artigo posterior, no qual o equívoco ou distorção entre interdisciplinaridade e aplicaçóes é apontado, ao afirmar: "Hoje, repensando esse resultado, constato uma distorção (...), pela não diferenciação entre interdisciplinaridade e aplicação. Na Ciência da Informação, as aplicaçóes (contextos, áreas, setores e organismos) isto é, a informação científica, tecnológica, industrial ou artística, ou a aplicação em campos do conhecimento, como na Medicina (informação em Medicina), se mesclam com a interdisciplinaridade propriamente dita. É fundamental esclarecer que uma área de aplicação pode apresentar contribuiçóes interdisciplinares, como é o caso da Biblioteconomia, que também é uma aplicação, por exemplo, em Automação de Bibliotecas enquanto, ao mesmo tempo, contribui para a representação da informação, com técnicas de catalogação, classificação e indexação" (Pinheiro, 1998).

A questáo é complexa e a nebulosidade conceitual que cerca conceitos tão próximos e ao mesmo tempo tão distantes é reconhecida por diferentes estudiosos. Pombo (2005), por exemplo, uma das maiores teóricas da interdisciplinaridade, denomina esses termos como "uma família de quatro elementos que se apresentam como mais ou 
menos equivalentes: pluridisciplinaridade, multidisplinaridade, interdisciplinaridade e transdisciplinaridade". A autora faz essa afirmativa em conferência proferida no Brasil, depois publicada na LIIN em revista, quando reconhece que "as suas fronteiras não estão estabelecidas, nem para aqueles que as usam, nem para aqueles que as estudam, nem para aqueles que as procuram definir", ao mesmo tempo em que considera que estas “... palavras estão muito gastas, muito banalizadas" (Pombo, 2005).

Assim como uma pintura impressionista, conhecida e reconhecida mundialmente, admirada por todos, mas impossível de ver, com nitidez, os seus contornos, também essa rede conceitual permanece numa certa penumbra crepuscular e talvez, exatamente por essas condiçóes, sedutora para aqueles que tentam vislumbrá-la com mais clareza e assim compreendê-la.

Nessa tentativa, a autora do presente trabalho incluiu o "campo interdisciplinar" no estudo do "domínio epistemológico", da Ciência da Informação, na sua pesquisa de doutorado iniciada em 1991 e intitulada, não por acaso, "A ciência da Informação entre sombra e luz" (Pinheiro, 1997). Esta pesquisa de cunho teórico foi complementada pela parte empírica, posteriormente atualizada até 2004 (Pinheiro, 2002,2006), na qual foram mapeadas as disciplinas da Ciência da Informação e as áreas com as quais são estabelecidos elos interdisciplinares, o que será discutido a partir do tópico 3.

\section{Interdisciplinaridade e transdisciplinaridade}

Embora a interdisciplinaridade, como tal denominada, tenha surgido no século 20, a sua noção ou percepção é muito mais antiga, da mesma forma que a sua prática, magistralmente representada por Leonardo da Vinci. Se, como o fez Morin (1997), retrocedermos até a antiguidade, é possível exemplificar com a noção de sistema ou, no século 17 pela figura de Pascal (1623-1662), na seguinte afirmativa: "eu considero impossível conhecer o todo se eu náo conheço as partes e conhecer as partes se eu não conheço o todo".

Outra idéia bastante aproximada é de Whewell (1794-1866), cientista com atuação em múltiplas áreas, notadamente na Filosofia e História da Ciência. No seu livro "The Philosophy of the inductive sciences" (1850) ele lança o conceito de "consiliente", significando o "salto conjunto do conhecimento entre e através das disciplinas, por meio da ligação de fatos e de teorias, para criar novas bases explanatórias”. Gilda Braga (1999) cita Whewell ao prefaciar uma coletânea sobre a interdisciplinaridade nas Ciências Sociais e na Ciência da Informação, reconhecendo que esta área é consiliente.

É interessante observar a similaridade entre a concepção de consiliente e a de transdisciplinaridade, manifestada no Primeiro Congresso Mundial de Transdisciplinaridade, em Portugal, no ano de 1994 (apud Japiassu, 2006): “abordagem científica, cultural, espiritual e social dizendo respeito ao que está entre as disciplinas, através das disciplinas e além de toda a disciplina".

Hoje, em nosso País, pesquisas sobre interdisciplinaridade e transdisciplinaridade aumentaram em número e aprofundaram as discussóes iniciais. Pombo (2005) considera que, "ao contrário de Portugal, onde as investigaçôes e experiências interdisciplinares são recentes e muito restritas, no Brasil há uma tradição ampla e já longa de trabalho interdisciplinar, tanto na investigação como no ensino". Ousamos dizer que no 
Brasil, embora talvez as iniciativas interdisciplinares sejam mais numerosas, são ainda em pequeno número os teóricos e pesquisas dedicados à questão, sistematicamente, e com, produção científica de longo alcance.

Em Portugal, desde os anos 1980 Olga Pombo integrava o Projecto Mathesis, sobre interdisciplinaridade, que gerou algumas publicaçóes sobre a questão, continuada em outro projeto, na Comissão Gulbenkian para reestruturação das Ciências Sociais e de âmbito internacional, com especialistas de diferentes ramos das Ciências Sociais, da natureza e das humanidades.

Em nosso País, o grande nucleador do pensamento interdisciplinar é Hilton Japiassu, que há mais de 35 anos vem pesquisando este fenômeno, iniciando com sua tese de doutorado, lançada no ano de 1976 como livro: "Interdisciplinaridade e patologia do saber" e que esta autora (Pinheiro,1997,1998,2002,2006) tem estudado em diversos artigos e comunicaçóes. Reunir suas idéias e tentar perceber confluências, ou não, com o pensamento de Olga Pombo, mencionada desde o início deste trabalho, além de um estimulante exercício intelectual e de aprendizagem é preciso - "navegar é preciso". Assim, este é objetivo do próximo tópico, reforçado pelo fato de os dois pesquisadores representarem países-irmáos (Brasil e Portugal) e pela produção de ambos ser das mais longas e contínuas sobre o pensamento interdisciplinar, em seus respectivos países, trilhando itinerários epistemológicos com a paixão e sensibilidade de um humanismo renovado e ampliado por seus olhares contemporâneos.

\subsection{Um diálogo imaginário além- mar: Hilton Japiassu e Olga Pombo}

Ao pensarem a origem da interdisciplinaridade Japiassu (1976) enfatiza a "necessidade de criar um fundamento ao surgimento de novas disciplinas", e os problemas epistemológicos das Ciências Humanas e Sociais, enquanto Pombo (1993) a enfatiza como proposta pedagógica, “uma 'aspiração' emergente no seio dos próprios professores”, sem deixar de sublinhar que o conceito de interdisciplinaridade "comporta duas vertentes", a epistemológica e a pedagógica, da mesma forma que o teórico brasileiro está atento às "motivaçôes próprias às necessidades do sistema universitário".

São vários os aspectos da interdisciplinaridade analisados por ambos e Japiassu, no seu livro de 1976, discute questóes como a origem do fenômeno interdisciplinar, as exigências do exercício interdisciplinar, noçôes, definiçóes, preocupaçôes (com a estrutura e os possíveis métodos comuns) e uma tipologia de interdisciplinaridade: linear ou cruzada, pseudo-interdisciplinaridade, interdisciplinaridade auxiliar, compósita, heterogênea e interdisciplinaridade unificadora. A cadeia conceitual traçada por Japiassu (1976) é pontuada pela multidisciplinaridade, pluridisciplinaridade, transdisciplinaridade e interdisciplinaridade, e seus respectivos conceitos, cuja ilustração, com base em Jantsch (1972), refletem "os graus sucessivos de cooperaçáo e de coordenação crescente das disciplinas".

Similarmente, na sua proposta de definição Pombo (2003) pensa esses conceitos como um "continuum" que parte da coordenação (pluridisciplinaridade), passa pela combinação (interdisciplinaridade) e chega à fusão (transdisciplinaridade).

Olga Pombo (1993), ao abordar os mesmos conceitos ressalta o radical comum "disciplinaridade", no que chamou "”longa família de palavras". Ao discutir a "diferença 
mínima” entre multidisciplinaridade e pluridisciplinaridade, a autora recorre a Gusdorf (responsável pelo prefácio do livro de Japiassu e muito naturalmente também citado pelo pesquisador brasileiro), que os considera equivalentes ou "simplesmente não os considera”. O aspecto etimológico é introduzido como possível explicação, por Pombo (1993), da "centralidade e caráter intermédio do conceito de interdisciplinaridade, sublinhado por Gusdorf (1990 apud Pombo, 1993): “o prefixo 'inter' não indica penas uma pluralidade, uma justaposição; evoca também um espaço comum, um factor de coesão entre saberes diferentes".

$\mathrm{Na}$ sua "contribuição para um vocabulário sobre a interdisciplinaridade", Pombo

(1994) abrange ampla terminologia sobre e relativa à interdisciplinaridade, incluindo variaçôes terminológicas e conceituais como interdisciplinaridade estrutural, unificadora, além de outras nâo tratadas por Japiassu (1976) como interdisciplinaridade de engrenagem, restritiva, com as respectivas explicitações.

Em trabalho apresentado em seminário internacional e intitulado "Epistemologia da Interdisciplinaridade”, Pombo (2003) retoma a discussão pelas palavras, iniciada por disciplina, reconhece "uma flutuação de conceitos mesmo no interior da palavra disciplina”. Mas há muito mais acrescentado e complementado, que reflete um entrecruzamento de idéias em diferentes aspectos relativos "as coisas, inversóes, reordenamentos disciplinares, teorizaçóes, alargamento", entre outros, dos quais destacaremos dois, por limite de extensão deste trabalho. No primeiro, as coisas, Pombo (2003) chama a atenção de "a partir de uma certo momento serem os próprios homens da ciência que se dão conta da gravidade das consequências da especialização que praticam"; e no segundo, em categorias divididas em ciência de fronteiras, interdisciplinas e interciências são identificadas as disciplinas que responderiam às particularidades de cada uma.

Outro ponto convergente dos autores em diálogo. na discussão da interdisciplinaridade, é Piaget (1972), não somente nessa definição, mas sobre transdisciplinaridade como "etapa" superior que sucede a das relaçôes interdisciplinares, a "...qual não só atingiria as interaçôes ou reciprocidades entre investigações especializadas, mas também se situaria estas no interior de um sistema total, sem fronteiras estáveis entre as disciplinas".

Trinta anos depois da sua obra sobre interdisciplinaridade, Japiassu publica o livro "O sonho transdisciplinar e as razóes da filosofia" (2006) no qual, como não poderia deixar de ser, retoma questóes estudadas no primeiro e, ouso dizer, transparece um pensamento náo somente conciliador como complementar e ampliado dos conceitos, permeando o seu discurso em diferentes momentos em especial quando explica a expressão que dá título ao seu livro: “...Por sonho transdisciplinar entendo o lugar geométrico mais ou menos utópico onde deveria manifestar-se o conjunto dessas estratégias, tendo por finalidade a compreensáo do mundo presente numa perspectiva utópica de unificação de conhecimentos”. Ou quando defende o movimento dialético não somente entre o local e global, "mas o de retroaçáo do global ao particular", contextualizando o singular e concretizando o global. Ou, ainda, quando manifesta a possibilidade da criaçáo de um campo do conhecimento no qual seja possível um novo paradigma ou o diálogo entre filósofos e cientistas, num território livre de hierarquias "entre esses diversos modos de problematização e experimentação" (Japiassu, 2006). Nesse sentido, percebe lacunas na idéia geral de interdisciplinaridade pois "não basta 
mais o simples encontro ou justaposição de disciplinas. Torna-se imprescindível eliminar as fronteiras entre as problemáticas e os modos de expressão presentes para que se instaure uma comunicação realmente fecunda e mais profunda entre os saberes precisando se unir e convergir numa efetiva concertação globalizadora”.

Finalmente, recorre à pesquisa de Dogan e Pahre (apud Japiassu, 2006), na constatação de que “...a maioria das atuais inovaçóes teóricas nas ciência sociais acontece nas margens híbridas dessas disciplinas...”

\section{Interdisciplinaridade na Ciência da Informação}

A natureza interdisciplinar da Ciência da Informação foi observada desde as primeiras formulaçóes conceituais da área, que datam do início dos anos 1960. Nessa fase, os conceitos e definiçóes desse novo campo que aflorava entre as Ciências Sociais Aplicadas, muito naturalmente ao incorporarem a interdisciplinaridade, não ultrapassavam a identificação das áreas interdisciplinares, sem, no entanto, explicitaçóes. Só para citar um exemplo, Borko (1968), num artigo que se tornou clássico, enumera as seguintes áreas: Matemática, Lógica, Linguística, Psicologia, Tecnologia de computador, Pesquisa de operações, Artes gráficas, Comunicação, Biblioteconomia e Administração.

A maioria dos estudiosos, nessa fase inicial da década de 1960 e mesmo na seguinte, apontam campos interdisciplinares sem o aprofundamento da questão.

Entre as exceçốes estão Merta (1968) e Mikahilov e colaboradores (1969). O primeiro destaca os seguintes campos do conhecimento, nos quais há um diálogo interdisciplinar com a Ciência da Informação, com as explanaçóes relativas a cada contribuição, entre as quais as metodológicas: Matemática e Lógica Matemática; Linguística e Semiótica; Cibernética e Teoria Matemática da Comunicação; Reprografia e Teoria do Conhecimento Automático; e Engenharia de Sistemas.

Já Mikhailov, Chernyi e Gilyarevskyi (1969) expóem como se concretizam as relaçóes da Ciência da Informação com a Semiótica, a Psicologia e a Biblioteconomia.

Mais recentemente, um autor dos mais produtivos e influentes na Ciência da Informação, Tefko Saracevic (1992), aborda as razóes interdisciplinares da Ciência da Informação com a Ciência Cognitiva, Comunicação, Ciência da Computação, e Biblioteconomia, concentradas nas duas últimas áreas, num artigo posterior de 1999 sobre a mesma temática.

Na sua tese, quando Pinheiro (1997) mapeou as disciplinas ou subáreas da Ciência da Informação com suas respectivas áreas interdisciplinares, conforme já citado, foi adotada como fonte o ARIST - Annual Review for Information Science and Technology, por sua relevância e legitimidade na área, no período de 1966 a 1995. Como a pesquisa foi depois atualizada até 2004, o período coberto foi razoavelmente longo, 38 anos, o que possibilitou acompanhar o desenvolvimento da construção epistemológica da área, refletida nas suas disciplinas, algumas consolidadas (as que aparecem desde o início da Ciência da Informação) e outras emergentes - as surgidas a partir dos anos 1990, como Inteligência Competitiva, Gestão do Conhecimento, comunicação Científica Eletrônica, Mineração de Dados, Bibliotecas Digitais/Virtuais.

O resultado final é apresentado no quadro 1, ordenado segundo frequência das subáreas, da maior a menor freqüência, a partir de sistemas de informação. 
Quadro 1 - Subáreas / disciplinas da Ciência da Informação e áreas interdisciplinares

\begin{tabular}{|c|c|}
\hline Subáreas / disciplinas & Áreas interdisciplinares \\
\hline 1. Sistemas de informação & Administração, Ciência da Computação \\
\hline 2. Tecnologia da informação & Ciência da Computação \\
\hline 3. Sistemas de recuperação da informação & $\begin{array}{l}\text { Biblioteconomia, Ciência da Computação e } \\
\text { Lingüística }\end{array}$ \\
\hline 4. Políticas de informação & Administração, Ciência Política e Direito \\
\hline 5. Necessidades e usos de informação & $\begin{array}{l}\text { Arquivologia, Biblioteconomia, Museologia e } \\
\text { Psicologia }\end{array}$ \\
\hline 6. Representação da informação & $\begin{array}{l}\text { Arquivologia, Biblioteconomia, Filosofia, } \\
\text { Lingüística e Museologia }\end{array}$ \\
\hline 7. Teoria da Ciência da Informação & $\begin{array}{l}\text { Epistemologia, Filosofia, Filosofia da Ciência e } \\
\text { Matemática }\end{array}$ \\
\hline 8. Formação e aspectos profissionais & Educação, Ética e Direito \\
\hline 9. Gestấo da informação & Administração, Economia e Estatística \\
\hline 10. Bases de dados & Ciência da Computação \\
\hline 11. Processamento automático da linguagem & $\begin{array}{l}\text { Biblioteconomia, Ciência da Computação e } \\
\text { Lingüística }\end{array}$ \\
\hline 12. Economia da informação & Administração e Economia \\
\hline 13. Bibliometria & $\begin{array}{l}\text { Estatística, História da Ciência, Matemática e } \\
\text { Sociologia da Ciência }\end{array}$ \\
\hline $\begin{array}{l}\text { 14. Inteligência competitiva e Gestáo do } \\
\text { conhecimento }\end{array}$ & Administração e Economia \\
\hline 15. Mineração de dados & Ciência da computação \\
\hline 16. Comunicação científica eletrônica & $\begin{array}{l}\text { Ciência da Computação, Comunicação, História } \\
\text { da Ciência e Sociologia da Ciência }\end{array}$ \\
\hline 17. Bibliotecas digitais/virtuais & $\begin{array}{l}\text { Biblioteconomia, Ciência da Computação e } \\
\text { Comunicaçáo }\end{array}$ \\
\hline
\end{tabular}

Considerando a presença maior ou menor de campos do conhecimento interdisciplinares, em relação a cada disciplina ou subárea da Ciência da Informação, predomina a Ciência da Computaçáo, presente em 8 disciplinas, seguida da Biblioteconomia e Administração, em 5; e Economia e Lingüística, que aparecem nos entrecruzamentos com 3 disciplinas ou subáreas.

Outra mudança observada diz respeito a subáreas que ganharam relevância e se consolidaram em função do aparato tecnológico que as sustenta, como comunicação científica eletrônica, hoje intensamente estudada, e a Bibliometria / informetria, que passou a dispor de softwares específicos para o processamento dos dados. Ainda em função das tecnologias de informação e comunicação -TIC's surgiram novas subáreas, a partir dos anos 1990, como Bibliotecas digitais, e Mineraçáo de dados, ou as decorrentes da globalização e da acirrada competitividade de mercados, como a Inteligência Competitiva e a Gestão do Conhecimento (Pinheiro, 2002,2006).

Para finalizar este tópico, uma nova reflexão se impóe, a partir de Pombo(2003), no que se refere aos reordenamentos disciplinares, expostos em três tipos: ciências de fronteira,interdisciplinas e interciências, já citadas. Quando a autora exemplifica as interciências com a Ecologia, nos remete a Wersig (1993), ao pensar a Ciência da 
Informação como protótipo de ciência pós-moderna, juntamente com a Ecologia. Para o autor, ambas diferem das ciências clássicas, originam-se da mudança revolucionária do papel do conhecimento no mundo contemporâneo, em dimensôes filosóficas e tecnológicas, e seu surgimento é impulsionado pela necessidade de estratégias para solução de problemas causados pela ciência e tecnologia.

\section{Indícios interdisciplinares nos Programas de Pós-Graduação em Ciência da Informação}

A interdisciplinaridade está no centro do debate nas universidades não somente como resposta aos imperativos de mudança, em razão da constatação da necessidade de uma nova abordagem para a formação acadêmica, mais plural, integrada e universal, mas não deslocada do local, considerando a desintegração e atomizaçáo dos saberes, como também pelo reconhecimento de que a interdisciplinaridade passa, necessariamente, por uma pedagogia interdisciplinar.

Não por acaso, o Congresso de Lucarno (Suíça), em 1997, promovido pela UNESCO e o Centre International de Recherches et Études Transdisciplinaires, reuniu Ciência e Educação, com o objetivo de "buscar novas diretrizes para a universidade do próximo século (XXI), pois a atual se encontra ameaçada pela ausência de sentido e por sua recusa em compartilhar os conhecimentos" (apud Japiassu, 2006)

Elegemos como focos de observação do movimento interdisciplinar nas universidades as chamadas áreas de concentração e as linhas de pesquisa, que norteiam o desenvolvimento dos programas e cursos de pós-graduação, hoje totalizando 11 (onze), conforme mostra o quadro seguinte. É necessário explicitar que para uma visão mais completa que pudesse ilustrar a evolução desses programas, neste quadro foi mantido o curso do IBICT iniciado com a UFRJ/ECO, depois com a UFF, e hoje continuado em novo convênio do IBICT com a UFRJ/FACC, bem como o da PUCCAMP, não mais credenciado pela CAPES, desde 2007 e com atividades suspensas.

Quadro 2 - Cursos e Programas de Pós-Graduação em Ciência da Informação, por cronologia de implantação

\begin{tabular}{|l|l|l|l|l|}
\hline $\begin{array}{l}\text { Universidade/ } \\
\text { Instituição }\end{array}$ & Cidade & Programa / Curso & \multicolumn{2}{|l|}{ Ano de Criaçáo } \\
\cline { 4 - 5 } $\begin{array}{l}\text { IBICT-UFRJ } \\
\text { IBICT-UFF }\end{array}$ & Rio de Janeiro & $\begin{array}{l}\text { Programa de Pós-Graduação } \\
\text { em Ciência da Informação }\end{array}$ & $\begin{array}{l}1970-2001 \\
2004-2008\end{array}$ & $\begin{array}{l}1994-2001 \\
2004-2008\end{array}$ \\
\hline IBICT-UFRJ & Rio de Janeiro & $\begin{array}{l}\text { Programa de Pós-Graduação } \\
\text { em Ciência da Informação }\end{array}$ & 2009 & 2009 \\
\hline UFMG & Belo Horizonte & $\begin{array}{l}\text { Programa de Pós-Graduação } \\
\text { em Ciência da Informação }\end{array}$ & 1976 & 1997 \\
\hline UFPB & João Pessoa & $\begin{array}{l}\text { Mestrado em Ciência da } \\
\text { Informação }\end{array}$ & 1977 & - \\
\hline PUCCAMP & Campinas & $\begin{array}{l}\text { Mestrado em Ciência da } \\
\text { Informação }\end{array}$ & $1977-2007$ & - \\
\hline
\end{tabular}




\begin{tabular}{|l|l|l|l|l|}
\hline UnB & Brasília & $\begin{array}{l}\text { Programa de Pós-Graduação } \\
\text { em Ciência da Informação }\end{array}$ & 1978 & 1992 \\
\hline USP* & São Paulo & $\begin{array}{l}\text { Programa de Pós-Graduação } \\
\text { em Ciência da Informação }\end{array}$ & 1972 & 1992 \\
\hline UNESP & Marília & $\begin{array}{l}\text { Programa de Pós-Graduação } \\
\text { em Ciência da Informação }\end{array}$ & 1998 & 2005 \\
\hline UFBA & Salvador & $\begin{array}{l}\text { Mestrado em Ciência da } \\
\text { Informação }\end{array}$ & 1998 & - \\
\hline UFSC & Florianópolis & $\begin{array}{l}\text { Mestrado em Ciência da } \\
\text { Informação }\end{array}$ & 2003 & - \\
\hline UFF & Rio de Janeiro & $\begin{array}{l}\text { Mestrado em Ciência da } \\
\text { Informação }\end{array}$ & 2008 & - \\
\hline UEL & Londrina & $\begin{array}{l}\text { Mestrado Profissional em } \\
\text { Gestâo da Informação }\end{array}$ & 2008 & - \\
\hline UFPE & Recife & $\begin{array}{l}\text { Mestrado em Ciência da } \\
\text { Informação }\end{array}$ & 2009 & - \\
\hline
\end{tabular}

*O Programa da USP, anteriormente vinculado ao de Comunicação, somente a partir de 2006 foi credenciado pela CAPES como autônomo, específico em Ciência da Informação.

Num total de 11 cursos em atividade, somente um é mestrado profissional, o da UEL,também o único não voltado à área como um todo (Ciência da Informação) e sim à Gestão da Informação, o que é pertinente à sua natureza e bastante atual. Todos os demais são acadêmicos e prevalecem cursos federais, numa total de 9, sendo os outros dois estaduais (UNESP e UEL).

Verifica-se que a década de 1970 foi pródiga na implantação de cursos de pósgraduação em Ciência da Informação no Brasil, período que corresponde à efervescência de programas de pós neste País, o que pode corresponder à consolidação e expansão de organismos criados para apoiar o ensino de pós-graduação e a pesquisa, o CNPq, fundado 1941 e a CAPES, em 1951.

Essas iniciativas voltaram a emergir nos anos 1990 e 2000, o que parece ser resultante da implantação da infraestrutura de rede no Brasil, a RNP-Rede Nacional de Pesquisas, hoje Rede Nacional de Ensino e Pesquisa, que dotou o Brasil da infraestrutura tecnológica necessária à operacionalização da Internet e Web. A Ciência da Informação esteve, desde o seu início, fortemente atrelada às tecnologias e este pode ter sido um fator decisivo para a implantação de novos cursos, tanto que um destes, o da UNESP inclui, entre as áreas de concentração, as tecnologias.

Chama a atenção nesse conjunto de programas, que há uma concentração de cinco cursos na regiáo sudeste, a mais desenvolvida econômica e socialmente, num total de 5 (IBICT-UFRJ,UFMG,USP,UNESP, e UFF), enquanto a região Norte não conta com nenhum.

\subsection{Vinculaçôes acadêmicas de Programas de Pós-Graduação em Ciência da Informação na estrutura universitária}

As vinculações dos programas de pós-graduação na estrutura universitária são, de certa forma, duplo indicadoras, pois tanto deixam transparecer a sua natureza, na 
medida em que integram um campo maior, por exemplo, as Ciências Sociais Aplicadas, quanto também podem traduzir laços interdisciplinares que os orientam, ou mesmo o status acadêmico e científico de uma área na universidade, quando chegam a constituir institutos ou faculdades independentes.

Os onze programas de pós-graduação estão assim distribuídos quanto à sua vinculação acadêmica:

Escola de Ciência da Informação (UFMG); Centro de Ciências Sociais Aplicadas (UFPB); Faculdade de Economia, Administração, Contabilidade e Ciência da Informação e Documentação - FACE/Departamento de Ciência da Informação e Documentação - CID (UnB) Faculdade de Administração e Ciências Contábeis - FACC/UFRJ (IBICT-UFRJ); Escola de Comunicaçôes e Artes - ECA (USP); Faculdade de Filosofia e Ciências (UNESP); Instituto de Ciência da Informação (UFBA); Instituto de Arte e Comunicação Social - IACS/ Departamento de Ciência da Informação (UFF); Centro de Ciências da Educação Departamento de Ciência da Informação (UFSC) Centro de Educação, Comunicação e Artes/Departamento de Ciência da Informação (UEL); Centro de Artes e Comunicação /Departamento de Ciência da Informaçáo/ (UFPE).

Predominam, num total de 4, as vinculaçóes a Centros e Escolas de Comunicação e Artes (USP,UFPE, UFF e UEL, onde está incluída também a Educação), seguidas de dois programas que funcionam ligados à Faculdade de Administração e Ciências Contábeis (IBICT-UFRJ e UNB, nesta Universidade abrangendo também Economia, além de Ciência da Informação e Documentação).

Se considerarmos estudos teóricos sobre a interdisciplinaridade na Ciência da Informação, constatamos que Tefko Saracevic (1992), conforme foi exposto anteriormente, inclui a Comunicação como uma das áreas mais fortemente interdisciplinares à Ciência da Informação, além da Ciência da Computação, a Ciência Cognitiva e a Biblioteconomia. Entretanto, não aparece vínculo com as áreas tecnológicas, presentes em pesquisa no exterior e também no Brasil, embora com menor ênfase, mas transparece o fortalecimento com a Administração.

\section{2 Áreas de concentraçáo e linhas de pesquisa}

As áreas de concentração dos 11 programas de pós-graduação estudados oscilam entre temáticas muito amplas ou restritas, o que pode ser comprovado a seguir, em sequência alfabética: Cultura e Informação (USP); Dimensôes Contemporâneas da Informação e do Conhecimento (UFF); Gestão da Informação (UFSC); Gestão e Organização do Conhecimento (UEL); Informação e Conhecimento na Sociedade Contemporânea (UFBA); Informação e Mediaçōes Sociais e Tecnológicas para o Conhecimento (IBICT/UFRJ); Informação, Conhecimento e Sociedade (UFPB); Informação, Memória e Tecnologias (UFPE); Informação, Tecnologia e Conhecimento (UNESP); Produção, organização e utilização da informação (UFMG); Transferência da informação na sociedade $(\mathrm{UnB})$.

O dado mais significativo neste resultado é a presença, na quase totalidade dos programas, de informação, seja isolada ou juntamente com o conhecimento, o que é muito coerente com a área, cujo objeto de estudo é a informação, não como um elemento isolado, mas na sua relação com o conhecimento, em processos cognitivos 
e nas mediaçóes sociais e tecnológicas. As tecnologias permeiam três programas, uma vez que a área é fortemente vinculadas às TIC's, além da gestão da informação e do conhecimento, esta última como decorrência da competitividade oriunda da globalização, conforme já ressaltado.

As linhas de pesquisa são apresentadas no quadro 3 e de certa forma, ratificam as tendências verificadas nas áreas de concentração, neste caso, de acentuado predomínio a preocupação com a gestão, em três áreas o que, se somado às quatro de organização, pela forte conotação gerencial, traduz bem tanto os aspectos econômico- financeiros quanto os de processamento e recuperação da informação, que se acentuaram com a Internet.

Quadro 3 - Linhas de pesquisa dos Programas de Pós-Graduação em Ciência da Informação

\begin{tabular}{|l|l|}
\hline Acesso a informação (USP) & Informação, sociedade e gestão estratégica (IBICT-UFRJ) \\
\hline Arquitetura da informação (UnB) & Mediação e ação cultural (USP) \\
\hline Comunicação da Informação (UnB) & Memória da informação científica e tecnológica ( UFPE) \\
\hline $\begin{array}{l}\text { Epistemologia e interdisciplinaridade na } \\
\text { Ciência da Informação ( IBICT-UFRJ) }\end{array}$ & $\begin{array}{l}\text { Memória, organização, produçáo e uso da informaçáo } \\
\text { (UFPB) }\end{array}$ \\
\hline $\begin{array}{l}\text { Ética, gestão e políticas de informação } \\
\text { (UFPB) }\end{array}$ & Organização da informação (UNESP) \\
\hline Fluxos de informação ( UFSC) & $\begin{array}{l}\text { Organização e compartilhamento da informação e do } \\
\text { conhecimento (UEL) }\end{array}$ \\
\hline $\begin{array}{l}\text { Fluxos e mediaçães sócio -técnicas da } \\
\text { informação (UFF) }\end{array}$ & $\begin{array}{l}\text { Organização, estrutura e fluxos de informação (IBICT- } \\
\text { UFRJ) }\end{array}$ \\
\hline $\begin{array}{l}\text { Gestão da informação e do } \\
\text { conhecimento (UFMG e UnB) }\end{array}$ & Organização e uso da informação ( UFMG) \\
\hline $\begin{array}{l}\text { Gestão, mediação e uso da informação } \\
\text { (UNESP) }\end{array}$ & Políticas, tecnologias e usos da informação (UFBA) \\
\hline $\begin{array}{l}\text { Informação, cultura e sociedade } \\
\text { (UFMG e UFF) }\end{array}$ & Produção, circulação e mediação da informação (UFBA) \\
\hline Informação e tecnologia (UNESP) & Profissionais de informação (UFSC) \\
\hline
\end{tabular}

\section{Configurações disciplinares, interdisciplinares e transdiciplinares}

Com relação às áreas de concentração e linhas de pesquisa de programas de pósgraduação em Ciência da Informação, alguns aspectos da análise são sugestivos e denotam como uma disciplina ou subárea pode evoluir, no interior desse campo, na sua conformação epistêmica, processo similar à progressão ou mutaçóes interdisciplinares que ocorrem numa área em relação a outras. Foram constatados, por exemplo: a incorporação de uma disciplina, emergente ou muito específica, noutra que consolidou o seu estatuto epistêmico ou, inversamente, o deslocamento de uma disciplina antes estudada no interior de outra e posteriormente autônoma ou, ainda, disciplinas muito amplas que se fragmentaram.

Nos estudos originados de sua tese, Pinheiro $(1997,1988,2002,2006)$ teve como fonte a produção intelectual do exterior e, nesse sentido, quando comparada aos resultados de áreas e linhas de pesquisa, tanto pontua o grau de inserção da pesquisa e ensino 
neste País, no campo teórico e prático contemporâneo da Ciência da Informação, quanto revela algumas tendências que podem, no seu processo evolutivo. atender a necessidades, demandas e prioridades nacionais.

Especificamente sobre a interdisciplinaridade, este trabalho fortalece, com algumas nuances e variaçôes, resultados de outras pesquisas da autora (Pinheiro 2006), a mais evidente a gestão da informação e do conhecimento, decorrente dos fenômenos que impulsionaram a Sociedade da Informação - a globalização e as tecnologias de rede - o que foi constatado tanto nas áreas de concentração quanto nas linhas de pesquisa e vinculações acadêmicas, nas primeiras a gestão e as atividades relacionadas ao processo gerencial e na segunda o vínculo hierárquico com as Faculdades de Administração.

Finalmente, se considerarmos como marco científico da Ciência da Informação a sua primeira formulação conceitual, em 1961/62, ainda que indícios de seu nascimento datem do final do século 19 e, ainda, que esta nova área seria, por sua natureza , uma interciência, não é possível ainda vislumbrar, nessa "galáxia de disciplinas", tanto no seu núcleo como nos seus contornos,onde tudo está em movimento, nem sua conformação epistêmica, nem seus horizontes, embora se anunciem em profusas irradiaçôes

\section{Referências bibliográficas}

BRAGA, Gilda Maria. Prefácio. In: Ciência da Informação, ciências sociais e Interdisciplinaridade. Org. por Lena Vania Ribeiro Pinheiro. Brasília, Rio de Janeiro: IBICT/DDI/DEP, 1999. p.9-10.

JAPIASSU, Hilton. Interdisciplinaridade e patologia do saber. Rio de Janeiro: Imago, 1976. 221 p. (Série Logoteca).

JAPIASSU, Hilton. O sonho transdisciplinar e as razôes da Filosofia. Rio de Janeiro: Imago, 2006.

MORIN, Edgard. Réforme de pensée, transdisciplinarité, reforme de l'Université. Communication. In: Congrès International "Quelle Université pour demain? Vers une evolution transdisciplinaire de l'Université. Locarno, Suisse, 30 avril -2 mai 1977. Publicado na Motivation, v.24, 1997. Disponível em: http://nicol.club.fr/ciret/bulletin/b12/b12cl.htm

PINHEIRO, Lena Vania R. Ciência da Informação: desdobramentos disciplinares, interdisciplinaridade e transdisciplinaridade. In: GONZÁLEZ DE GÓMEZ, Maria Nélida; ORRICO, Evelyn Goyannes Dill. (Org.). Políticas de memória e informação: reflexos na organização do conhecimento. Natal: Editora Universitária da UFRN/EDUFRN, 2006, p. $111-141$.

PINHEIRO, Lena Vania Ribeiro. Campo interdisciplinar da Ciência da Informação:fronteiras remotas e recentes. Investigación Bibliotecológica, México, v.12, n.25, p.132-163, 1998. Disponível em: <http://biblioteca.ibict.br/phl8/anexos/Mexicolena.pdf>. Publicado também no Brasil em coletânea do IBICT.

PINHEIRO, Lena Vania Ribeiro. Ciência da Informação entre sombra e luz: domínio epistemológico e campo interdisciplinar. Rio de Janeiro: 1997. 278p. Tese(Comunicação e Cultura) UFRJ/ECO. Orientadora: Gilda Braga. Disponível em: <http://biblioteca.ibict. $\mathrm{br} / \mathrm{phl8/anexos/lenavaniapinheiro1997.pdf>}$

PINHEIRO, Lena Vania Ribeiro. Ciência da Informação: questôes sobre formação, ensino e pesquisa (coluna). DatagramaZero, Rio de Janeiro, v.3, n.5, out. 2002. Disponível em: www.dgzero.org/out02/F_I_com.htm 
POMBO, Olga. (1994). Contribuição para um vocabulário sobre interdisciplinaridade. In: POMBO, Olga; LEVY, Teresa; GUIMARÃES, Henrique (Org.). A interdisciplinaridade: reflexão e experiência. 2. ed. Lisboa: Texto. Disponível em:http://www .educ.fc.ul.pt/ docentes/opombo/mathesis/vocabulario-interd.pdf .

POMBO, Olga. Epistemologia da Interdisciplinaridade. In: Seminário Internacional Interdisciplinaridade, Humanismo, Universidade, 2003. Porto. Anais... Universidade do Porto. Disponível em: http://www.humanismolatino.online.pt/v1/pdf/C002_11.pdf.

POMBO, Olga. (1993). Interdisciplinaridade: conceito, problema e perspectiva. In:

A interdisciplinaridade: reflexáo e experiência. Lisboa: Universidade de Lisboa. Disponível em: http://www.educ.fc.ul.pt/docentes/opombo/mathesis/inter disciplinaridade .pdf.

POMBO, Olga. (2005). Interdisciplinaridade e integração dos saberes. Liinc em revista, 1, 3-15. Disponível em: http://revista.ibict.br/liinc/index.php/liinc/article/view/186/103.

SARACEVIC, Tefko. Information Science: origin, evolution and relations. In: VAKKARI, Pertti, CRONIN, Blaise, ed. Conceptions of Library and Information Science; historical, empirical and theoretical perspectives. Proceedings of the International Conference for the celebration of 20th anniversary of the Department of Information Studies, University of Tampere, Finland, 26-28, 1991. London, Los Angeles: Taylor Graham, 1992. p. 5-27

WHEWELL, William. The Philosophy of the inductive sciences founded upon their history. London: John W. Parker, 1847. 2v. 